\title{
Geographical distribution of cases of Creutzfeldt-Jakob disease in England and Wales 1970-84
}

\author{
S N Cousens, R Harries-Jones, R Knight, R G Will, P G Smith, W B Matthews
}

\begin{abstract}
Two hundred and sixty seven patients with a definite or probable diagnosis of Creutzfeldt-Jakob disease (CJD) were identified in an attempt to ascertain all cases of the disease in England and Wales in the period 1970-84. No evidence of space-time clustering of dates and places of onset was found for these cases. Two age- and sex-matched controls were selected for 72 of the 122 cases diagnosed in the period 1980-84 and life histories of places of residence were obtained for these cases and the controls. No evidence was found that cases had lived closer to each other than had controls at any time in their lives, except that there was an excess of cases born in London. The study does not provide supportive evidence for case-to-case transmission of CJD being an important component in the aetiology of the disease.
\end{abstract}

Creutzfeldt-Jakob disease (CJD) has been known to be experimentally transmissible since $1968,{ }^{1}$ but despite epidemiological investigation in several countries ${ }^{2-5}$ the mechanism of natural transmission remains obscure. Geographical aggregation of sporadic cases ${ }^{67}$ and the development of CJD in patients marrying into infected families ${ }^{346}$ provides some evidence for lateral transmission. However, the rarity of confirmed contact between cases and the low incidence of the condition has led to the hypothesis that the agent is an inherent component of the genome ${ }^{8}$ and that case-to-case transmission is exceptional. Fifteen cases of iatrogenic, lateral transmission have been reported with incubation periods ranging between 16 months and 23 years, ${ }^{9}$ but in the great majority this mechanism of cross-infection can be excluded. The prolonged incubation period in iatrogenic cases suggests that the search for geographic clustering should relate not only to the place of residence at diagnosis but to potential contact between cases in the past.

We report the results of a case-control study of all new cases of CJD in England and Wales between 1980-84, in which information on the place of residence from birth to onset of symptoms was sought to analyse retrospectively for geographical aggregation of cases. We also present analyses of the geographical and temporal distribution of all known cases of CJD in England and Wales in the 15 year period 1970-84.

\section{Methods}

The methods of case ascertainment and control selection have been described. ${ }^{10}$ In brief, neurological centres in England and Wales were circulated with requests to notify us of all known or suspected cases of CJD. Copies of all death certificates on which CJD or spongiform encephalopathy was mentioned were obtained from the Office of Population, Censuses and Surveys (OPCS). One of us (RHJ, RK or RGW) tried to see all suspected cases in life, often repeatedly, and EEG records were also examined. Otherwise, the patient's hospital notes were obtained. In addition, an attempt was made to recruit two control patients for each case, matched to the case for age ( \pm 4 years), sex and hospital. One control ("neurological") was selected from patients with a neurological disease impossible to mistake for CJD. A second control ("medical") was selected from patients with some non-neurological reason for admission.

By the time CJD is diagnosed patients are unable to communicate. A life history of places of residence was therefore obtained from a close relative. A similar interview was conducted with a relative of each control patient. Within each case-control trio we tried to interview relatives of a similar degree of closeness to the case or control. Wherever possible precise addresses and dates of moving were obtained. The map co-ordinates of each address were coded to the nearest kilometre by reference to Ordnance Survey maps. When the precise address was unknown, the map reference used was that of the town or village in which the subject had lived (for London this was taken to be Westminster), as recorded in the Ordnance Survey Gazetteer. When only the year of a move was known, it was assumed, for the purposes of analysis, that the move had taken place in the middle of the year. When the year of moving was unknown the place of residence between the last previous known date of moving and the next known date of moving was treated as unknown.

Thirty cases of CJD, out of a total of 122 , were excluded from the case-control analysis, the most common reasons for exclusion being the lack of an informed relative (12 cases) or undue delay in establishing the diagnosis (11 cases). The remaining seven cases were excluded for the following reasons: lack of medical cooperation (1), lack of cooperation of a relative (3), inability to find a "medical" control for patients admitted to a neurological hospital (3). In total, 92 sets of case and 
Table 1 Numbers of deaths from Creutzfeldt-Jakob disease in England and Wales by sex, 1970-84 ("definite" and "probable" cases only)

\begin{tabular}{|c|c|c|c|c|c|c|c|c|c|c|c|c|c|c|c|c|c|}
\hline \multirow[b]{2}{*}{ Sex } & \multicolumn{15}{|c|}{ Year of death } & \multirow[b]{2}{*}{ Total $\ddagger$} & \multirow[b]{2}{*}{ Rate $e^{\star}$} \\
\hline & 70 & 71 & 72 & 73 & 74 & 75 & 76 & 77 & 78 & $79 \dagger$ & 80 & 81 & 82 & 83 & 84 & & \\
\hline $\begin{array}{l}\text { Male } \\
\text { Female }\end{array}$ & $\begin{array}{l}3 \\
7\end{array}$ & $\begin{array}{l}4 \\
9\end{array}$ & $\begin{array}{l}3 \\
6\end{array}$ & $\begin{array}{l}8 \\
8\end{array}$ & $\begin{array}{l}8 \\
9\end{array}$ & $\begin{array}{l}2 \\
6\end{array}$ & $\begin{array}{r}4 \\
12\end{array}$ & $\begin{array}{r}7 \\
12\end{array}$ & $\begin{array}{l}10 \\
15\end{array}$ & $\begin{array}{r}5 \\
11\end{array}$ & $\begin{array}{r}8 \\
16\end{array}$ & $\begin{array}{l}10 \\
13\end{array}$ & $\begin{array}{r}9 \\
14\end{array}$ & $\begin{array}{r}9 \\
12\end{array}$ & $\begin{array}{l}13 \\
14\end{array}$ & $\begin{array}{l}103 \\
164\end{array}$ & $\begin{array}{l}0.29 \\
0.44\end{array}$ \\
\hline $\begin{array}{l}\text { Total } \\
\text { Rate* }\end{array}$ & 10 & 13 & $\begin{array}{c}9 \\
0.27\end{array}$ & 16 & 17 & 8 & 16 & $\begin{array}{c}19 \\
0.35\end{array}$ & 25 & 16 & 24 & 23 & $\begin{array}{c}23 \\
0 \cdot 49\end{array}$ & 21 & 27 & 267 & 0.37 \\
\hline
\end{tabular}

$\star$ Per million per year.

t The number of cases in the period 1970-79 is nine less than that previously reported as amyotrophic cases have been excluded see text).

${ }^{+}$Excludes four patients (three male, one female) reported in 1980-84 who survived into 1985.

control relatives were interviewed. In 70 sets the spouse was questioned and for most of the remainder a son or daughter was interviewed. For only seven cases and 11 controls was it necessary to interview a more distant relative.

\section{Diagnostic criteria}

These have been described previously. ${ }^{11}$ For a "definite" diagnosis of CJD the following were required: a history of rapidly advancing dementia, accompanied by varying combinations of the typical signs of CJD (myoclonus, other movement disorders, cortical blindness, cerebellar ataxia, rigidity, akinetic mutism) and histological confirmation of spongiform degeneration. Cases were classified as "probable" if they had similar clinical features to the above, accompanied by an EEG displaying 1-2 per second triphasic complexes, but with no histology available. Patients were classified as "possible" cases of CJD if they had the clinical features as above, but no histological confirmation or characteristic EEG was obtained. Patients with more gradual development of dementia, accompanied or followed by evidence of widespread neurogenic atrophy, usually severe, did not satisfy these criteria and, despite the occasional finding of spongiform degeneration at necropsy, probably did not have CJD. ${ }^{12}$

\section{Results}

A total of 249 patients were notified as suspected cases of CJD during the five year period
1980-84. One hundred and five of these cases were not thought to show the clinical or histological features of CJD, or were shown to have some other disease. This total included 16 persons with amyotrophy, none of whom conformed to the diagnostic criteria for "definite" or "probable" CJD. In addition, a further 22 patients were classified as "possible" cases. None of these 127 patients are considered in this report. Of the remaining 122 patients, 93 were classified as definite CJD and 29 as probable cases. The initial sources of information on the definite and probable cases were: neurologist (94 cases), pathologist (8), general physician (7), psychiatrist (2) and death certificate (11).

During the period $1980-84$ there was little variation in the annual number of deaths from CJD (definite and probable cases), whereas over the period 1970-79 there was a trend for the annual number of cases to increase (table 1). The average annual death rate from CJD was 0.49 per million during $1980-84$ and 0.31 per million during 1970-79.

Among cases reported during the period 1980-84 the mean age at death was $63 \cdot 1$ years (men 62.3 years; women 63.8 years; range $33-$ 82 years). Age- and sex-specific average annual mortality rates for the 118 definite and probable cases of CJD dying between 1980-84 are shown in fig 1a. Mortality rates rose rapidly between the ages of 40 and 70 years and fell considerably thereafter. While rates among women were higher than in men in the range 60-74 years, the rates for the two sexes appear
Figure 1 Age and sex specific mortality rates from Creutzfeldt-Jakob disease in England and Wales in the periods 1980-84 and 1970-79.

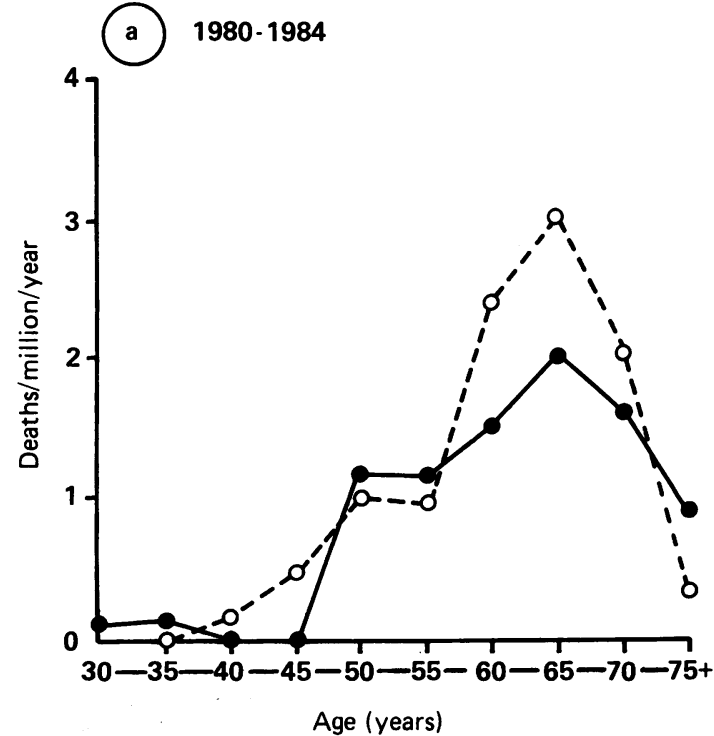

(b)

$1970-1979$

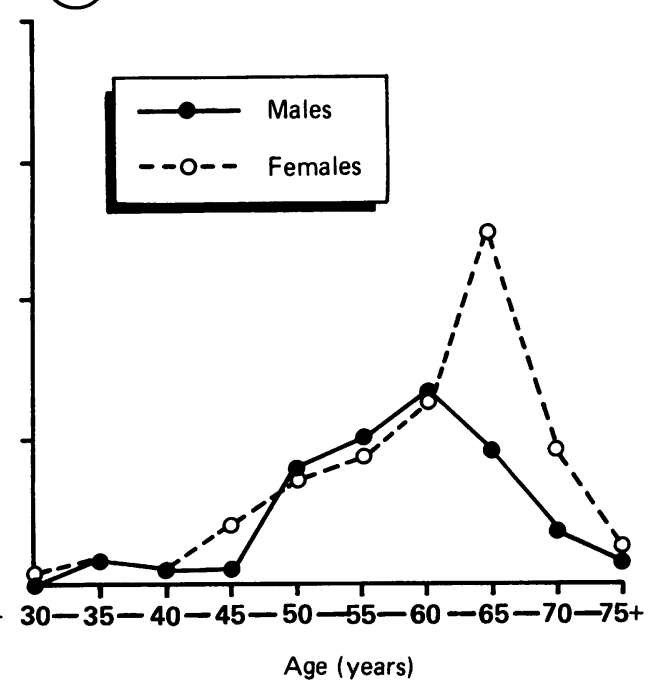


Figure 2 Geographical distribution of cases of Creutzfeldt-Jakob disease in England and Wales, 1970-79 and 1980-84.

Figure 3 Average annual mortality rates (per million) of CreutzfeldtJakob disease by county of England and Wales 1970 79 and 1980-84. Solid areas represent counties of highest incidence and blank areas of lowest incidence. (a)

$1970 \cdot 79$

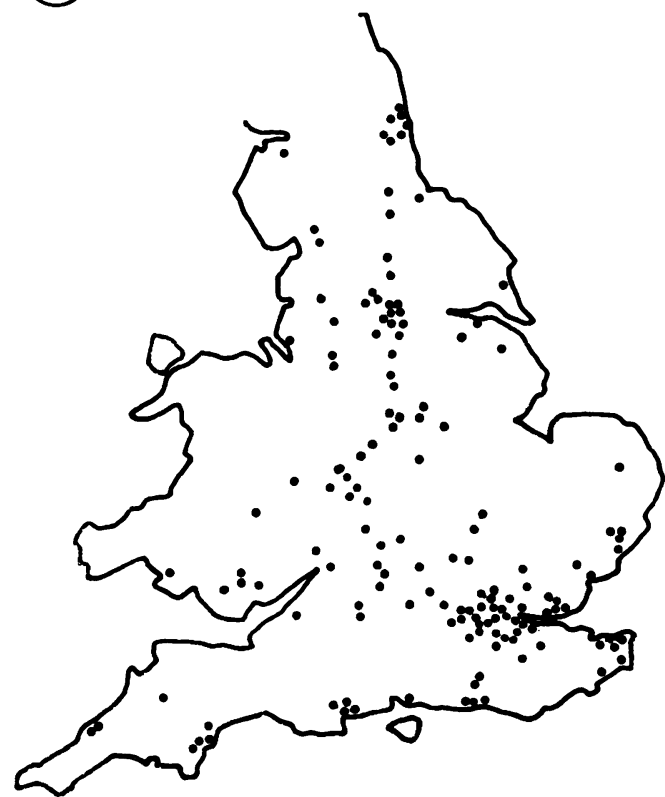

similar for those aged less than 60 years. There was, however, no evidence that this apparent difference in trends between the sexes had not arisen by chance $\left(\chi^{2}=11 \cdot 7 ; \mathrm{df}=9 ; \mathrm{p}>0 \cdot 2\right)$. Over the entire age range the incidence rate ratio for females versus males was 1.37 (95\% CI 1.07, 1.75). Comparable data for the years 1970-79 are shown in fig $1 \mathrm{~b}$. The general pattern is similar with higher rates among women at older ages and a decline in incidence rates in old-age among both sexes.

The locations of the places of residence of cases in the periods $1970-79$ and $1980-84$ are shown in fig 2. (The distribution of cases during the period 1970-79 includes nine amyotrophic cases. Such cases have been excluded from the 1980-84 series.) In 1970-79 there was a deficit of cases in the Merseyside conurbation (in north west England) ${ }^{2}$ but this

a $1970-1979$

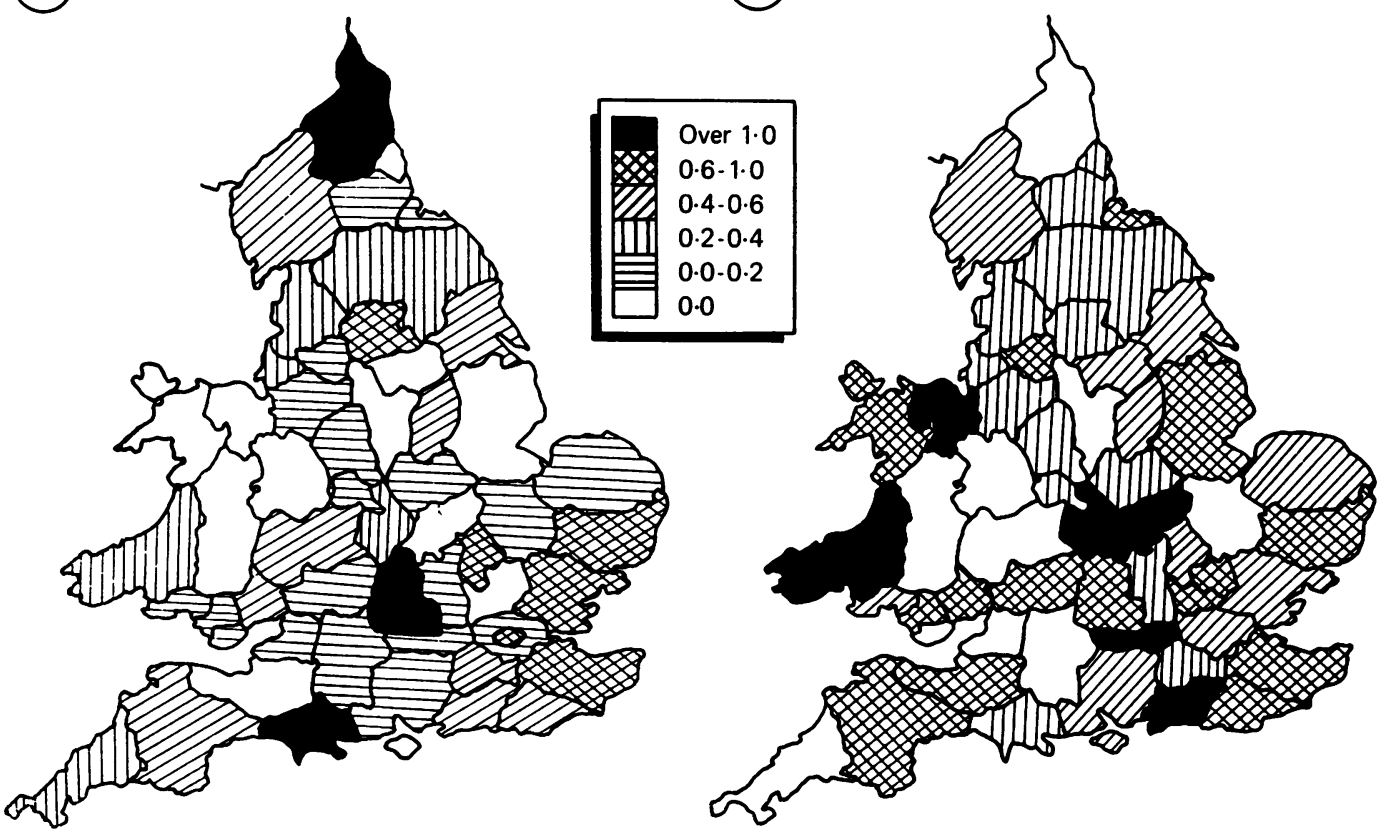

was not apparent in the $1980-84$ data. In contrast, no cases were observed around Newcastle upon Tyne (in the north east) in the period 1980-84 whereas there were seven cases in this area in the earlier period. Mortality rates of CJD by county for the periods 1970-79 and 1980-84 are shown in fig 3 . Will et al ${ }^{2}$ noted statistically significant variations in mortality rates between counties ( $p<0.001$ ) during the period 1970-79 but the variation between counties in 1980-84 was not significant. Will et $a l^{2}$ also reported significant variation in mortality rates between the nine standard regions in England and Wales ( $p<0.001)$, but this was not apparent in the 1980-84 data $\left(\chi^{2}=7 \cdot 5\right.$; df $=8 ; \mathrm{p}>0.05)$ (table 2). The geographical distribution of cases between the standard regions differed slightly between the periods 1970-79 and 1980-84 $\left(\chi^{2}=14 \cdot 3 ; \mathrm{df}=8 ; \mathrm{p}<\right.$ 
Table 2 Average annual mortality rates ${ }^{\star}$ for Creutzfeldt-Jakob disease by standard region in England and Wales, for the periods 1970-79 and 1980-84

\begin{tabular}{|c|c|c|c|c|}
\hline \multirow[b]{2}{*}{ Region } & \multicolumn{2}{|l|}{$1970-79$} & \multicolumn{2}{|l|}{$1980-84$} \\
\hline & No of deaths & Rate/million/year & No of deaths & Rate/million/year \\
\hline $\begin{array}{l}\text { Northern } \\
\text { Yorkshire and Humber } \\
\text { East Midlands } \\
\text { East Anglia } \\
\text { South East } \\
\text { South West } \\
\text { West Midlands } \\
\text { North West } \\
\text { Wales }\end{array}$ & $\begin{array}{r}11 \\
19 \\
7 \\
6 \\
67 \\
14 \\
10 \\
5 \\
5\end{array}$ & $\begin{array}{l}0.37 \\
0.41 \\
0 \cdot 20 \\
0.33 \\
0.42 \\
0.32 \\
0.21 \\
0.08 \\
0.18\end{array}$ & $\begin{array}{r}6 \\
9 \\
8 \\
4 \\
47 \\
9 \\
10 \\
13 \\
12\end{array}$ & $\begin{array}{l}0.39 \\
0.37 \\
0.44 \\
0.43 \\
0.79 \\
0.39 \\
0.41 \\
0.41 \\
0.84\end{array}$ \\
\hline Total & $149+$ & 0.30 & 118 & 0.49 \\
\hline
\end{tabular}

^Average annual mortality rate per million, standardised for age and sex.

$\dagger$ Total includes five cases who could not be allocated to a standard region.

$0 \cdot 10)$. This difference was due mainly to an excess of cases in Wales and the north west of England in 1980-84 compared with 1970-79. No evidence was found of any association between the incidence of CJD and population density (by county).

Evidence of clustering of cases in space and time was sought using methods due to Knox, ${ }^{13}{ }^{14}$ and to Pike and Smith. ${ }^{15}$ The former involves examining all possible pairs of cases to determine the number of pairs with onset of disease within a "critical" space and time distance of each other. This number is compared with the number expected, based on the assumption of no association between the time and place of onset of different cases. The method does not require control subjects. For patients diagnosed with CJD in the period 1980-84, place and approximate date of onset of symptoms were known for 120 of 122 cases. The results of the analysis for space-time clustering are shown in table 3. There was a slight excess of pairs of cases resident within five kilometres of each other and with onsets between three and six months apart (four observed, 1.6 expected), (one pair in Sunderland, one pair in Kent, three cases (two pairs) in Hounslow), and for cases resident within $20 \mathrm{~km}$ of each other and with onsets between six and 12 months apart ( 35 observed, 26.4 expected; $\mathrm{p}<0.05$ ).

Analyses were also conducted on data on all known cases in the period 1970-84. For these analyses 143 definite and probable cases from the period 1970-79 were added to the 1980-84 data. A significant excess $(p<0.05)$ of pairs was observed for cases occurring within $10 \mathrm{~km}$ of each other and five to six years apart ( 31 observed; 22.7 expected), within $20 \mathrm{~km}$ of each other and between six and 12 months apart (78 versus 62.5 ) and for cases occurring within $50 \mathrm{~km}$ of each other between two and three years apart (422 versus $372 \cdot 0$, table 4 ).

Indirect evidence of case-to-case transmission was sought using the Pike and Smith method. ${ }^{15}$ To use this method it is necessary to specify periods during which an individual is assumed to be "susceptible" to infection and during which she or he is "infectious". All pairs of cases are studied to determine whether the pair lived "close" to each other at a time when one was "infectious" and the other "susceptible", that is, when transmission from one to the other could have taken place. The expected number of such "contacts" between cases is computed by conducting similar analyses among the controls. Residence histories were available for 92 case-control trios. Slightly more complete information on places of residence was available for cases than for controls. For 78 (of 92) cases a complete lifetime residence history was obtained. Such histories were obtained from 73 of the medical controls and 66 of the neurological controls. In total the percentage of time for which a place of residence was not known was $3.7 \%$ for the cases and $6.0 \%$ and $6.4 \%$ for the medical and neurological controls, respectively. Most of the missing information was for the years before 1951.

Various susceptible and infectious periods were tried, beginning up to 25 years before death, with "critical" distances of $1,5,10$ or $20 \mathrm{~km}$. An example of the results of these analyses, using a critical distance of $10 \mathrm{~km}$, is shown in table 5 . There were 33 "contact years" between pairs of patients with CJD who lived within $10 \mathrm{~km}$ of each other at a time when

Table 3 Space-time clustering of dates and places of onset of 120 cases of Creutzfeldt-Jakob disease in England and Wales, 1980-84: observed and expected numbers of pairs of cases with onsets within "critical" time and space distances of each other

\begin{tabular}{|c|c|c|c|c|c|c|c|c|}
\hline \multirow{3}{*}{$\begin{array}{l}\text { Time } \dagger \text { between } \\
\text { dates of onset }\end{array}$} & \multicolumn{8}{|c|}{ Distance between places of residence at onset } \\
\hline & \multicolumn{2}{|c|}{$<5 \mathrm{~km}$} & \multicolumn{2}{|c|}{$<10 \mathrm{~km}$} & \multicolumn{2}{|c|}{$<20 \mathrm{~km}$} & \multicolumn{2}{|c|}{$<50 \mathrm{~km}$} \\
\hline & Obs & $\operatorname{Exp}$ & Obs & $\operatorname{Exp}$ & Obs & $\operatorname{Exp}$ & Obs & $\operatorname{Exp}$ \\
\hline $\begin{array}{l}<1 \text { month } \\
1-3 \text { months } \\
3-6 \text { months } \\
6-12 \text { months } \\
1-2 \text { years } \\
2-3 \text { years }\end{array}$ & $\begin{array}{l}0 \\
1 \\
4 \\
4 \\
3 \\
1\end{array}$ & $\begin{array}{l}0.6 \\
1 \cdot 2 \\
1 \cdot 6 \\
3.0 \\
5 \cdot 0 \\
3 \cdot 7\end{array}$ & $\begin{array}{l}0 \\
3 \\
5 \\
9 \\
7 \\
6\end{array}$ & $\begin{array}{r}1 \cdot 2 \\
2 \cdot 7 \\
3 \cdot 6 \\
6 \cdot 7 \\
11 \cdot 1 \\
8 \cdot 2\end{array}$ & $\begin{array}{r}4 \\
8 \\
9 \\
35 \\
48 \\
26\end{array}$ & $\begin{array}{l}4 \cdot 8 \\
10 \cdot 6 \\
14 \cdot 0 \\
26 \cdot 4^{\star} \\
43 \cdot 7 \\
32 \cdot 3\end{array}$ & $\begin{array}{r}14 \\
32 \\
47 \\
103 \\
155 \\
116\end{array}$ & $\begin{array}{r}17 \cdot 3 \\
38 \cdot 5 \\
50 \cdot 8 \\
95 \cdot 9 \\
158 \cdot 8 \\
117 \cdot 6\end{array}$ \\
\hline
\end{tabular}

${ }^{\star} p<0.05 .+$ Critical times used were (in days): $35,95,185,370,735,1100$. 
Table 4 Space-time clustering of dates and places of onset of 263 cases of Creutzfeldt-Jakob disease in England and Wales, 1970-84: observed and expected numbers of pairs of cases with onsets within "critical" time and space distances of each other

\begin{tabular}{|c|c|c|c|c|c|c|c|c|}
\hline \multirow{3}{*}{$\begin{array}{l}\text { Timet between } \\
\text { dates of onset }\end{array}$} & \multicolumn{8}{|c|}{ Distance between places of residence at onset } \\
\hline & \multicolumn{2}{|c|}{$<5 \mathrm{~km}$} & \multicolumn{2}{|c|}{$<10 \mathrm{~km}$} & \multicolumn{2}{|c|}{$<20 \mathrm{~km}$} & \multicolumn{2}{|c|}{$<50 \mathrm{~km}$} \\
\hline & Obs & $\operatorname{Exp}$ & Obs & $\operatorname{Exp}$ & Obs & $\operatorname{Exp}$ & Obs & $\operatorname{Exp}$ \\
\hline $\begin{array}{l}<1 \text { month } \\
1-3 \text { months } \\
3-6 \text { months } \\
6-12 \text { months } \\
1-2 \text { years } \\
2-3 \text { years } \\
3-4 \text { years } \\
4-5 \text { years } \\
5-6 \text { years } \\
6-7 \text { years } \\
7-8 \text { years } \\
8-9 \text { years } \\
9-10 \text { years }\end{array}$ & $\begin{array}{r}0 \\
2 \\
5 \\
9 \\
7 \\
6 \\
6 \\
13 \\
9 \\
8 \\
5 \\
10 \\
6 \\
7\end{array}$ & $\begin{array}{r}1 \cdot 1 \\
2 \cdot 2 \\
3 \cdot 2 \\
6 \cdot 2 \\
11 \cdot 7 \\
10.9 \\
10.0 \\
8 \cdot 7 \\
7 \cdot 7 \\
7.0 \\
6.0 \\
4.9 \\
4 \cdot 4\end{array}$ & $\begin{array}{r}0 \\
7 \\
9 \\
22 \\
28 \\
30 \\
26 \\
26 \\
31 \\
25 \\
20 \\
12 \\
14\end{array}$ & $\begin{array}{r}3 \cdot 1 \\
6 \cdot 5 \\
9 \cdot 3 \\
18 \cdot 2 \\
34 \cdot 4 \\
31 \cdot 9 \\
29 \cdot 3 \\
25 \cdot 3 \\
22 \cdot 7 \\
20 \cdot 4 \\
17 \cdot 8 \\
14 \cdot 4 \\
12 \cdot 9\end{array}$ & $\begin{array}{r}9 \\
16 \\
28 \\
78 \\
137 \\
110 \\
107 \\
86 \\
82 \\
75 \\
62 \\
38 \\
43\end{array}$ & $\begin{array}{c}10 \cdot 6 \\
22 \cdot 3 \\
31 \cdot 9 \\
62 \cdot 5^{\star} \\
117 \cdot 8 \\
109 \cdot 2 \\
100 \cdot 3 \\
87 \cdot 1 \\
77 \cdot 8 \\
69 \cdot 8 \\
60 \cdot 8 \\
49 \cdot 2 \\
44 \cdot 2\end{array}$ & $\begin{array}{r}30 \\
67 \\
116 \\
236 \\
393 \\
422 \\
362 \\
295 \\
258 \\
240 \\
198 \\
160 \\
146\end{array}$ & $\begin{array}{r}36 \cdot 0 \\
76 \cdot 1 \\
108 \cdot 6 \\
212 \cdot 8 \\
401.3 \\
372 \cdot 0^{\star} \\
341 \cdot 8 \\
296 \cdot 8 \\
265.2 \\
237 \cdot 8 \\
207 \cdot 2 \\
167.6 \\
150 \cdot 5\end{array}$ \\
\hline
\end{tabular}

${ }^{\star} \mathrm{p}<0.05 .+$ Critical times used were (in days): 35, 95, 185, 370, 735, 1100, 1465, 1830, 2195, 2560, 2925, 3285, 3655.

one was within one year of death and the other was within three years of death. The expected number of contact years (based on similar contacts between the controls) was $48 \cdot 7$. No evidence was found of excess case-to-case contact when using $10 \mathrm{~km}$ as the critical distance, or when using 1,5 or $20 \mathrm{~km}$.

Three further analyses of possible susceptible and infectious periods were undertaken (table 6). In the first, infection (susceptibility) was assumed to occur in the first year of life and infectivity was assumed to be life-long. One hundred and ten patient pairs were found in which one pair was born within $10 \mathrm{~km}$ of where the other "patient" was living at that time (obviously, long before the onset of disease). The expected number of such pairs was calculated to be 73.2 and the excess (110 versus 73.2 ) was significant $(p<0.05)$. In the second analysis the period of susceptibility, as well as the period of infectivity, was assumed to extend over the whole of life. There were 132 patient pairs so that, at any time in their lives, one of the patients lived within one kilometre of the other patient. The expected number of such pairs was $82.4(p<0.05)$. In the third analysis, the same infective and susceptible periods as in the second are assumed but the number of years in which patients lived within the specified distances of each other have been counted. None of the excesses observed in this analysis were statistically significant.

\section{Discussion}

During the period 1970-79 there was an increase in the incidence of detected cases of CJD in England and Wales, ${ }^{2}$ most likely due to incomplete case ascertainment in the earlier years. The approximately constant incidence during $1980-84$ is consistent with more uniform diagnostic or notification practices over this latter period. The non-random geographical distribution of cases in the earlier period may have a similar explanation, though it is not clear why there should be a deficit of cases in the Mersey area, which is well served by neurologists. This deficit was not apparent in the 1980-84 data and in this period there was no statistically significant variation in the incidence rates between different counties. It is probable that in this more recent period most of the cases of CJD that occurred in England and Wales were included in the study.

In the earlier series we described a relative excess of cases in older women and a steep decline in incidence rates among both sexes after the age of about 70 years. Similar features are present in the 1980-84 cases. The female excess has been described in some other series, including that reported from France for cases between $1977-82 .{ }^{3}$ We have no explanation for this female excess. The rapidity with which the mortality rate declines after the age of 65 to 70 years is remarkable. In part this may be due to poor case ascertainment among old persons but the clinical features of the disease are sufficiently distinctive that this may not be the complete explanation. A similar fall in mortality rates at older ages has been described in the French series. ${ }^{3}$

Table 5 The number of years pairs of cases of Creutzfeldt-Jakob disease were living within $10 \mathrm{~km}$ of each other when one was assumed to be "susceptible" and the other "infectious". Analysis based on 92 cases diagnosed in the period 1980-84 and 184 matched controls"

\begin{tabular}{|c|c|c|c|c|c|c|c|c|c|c|c|c|c|c|c|c|}
\hline \multirow{3}{*}{$\begin{array}{l}\text { Assumed } \\
\text { period of } \\
\text { infectivity }\end{array}$} & \multicolumn{16}{|c|}{ Assumed period of susceptibility } \\
\hline & \multicolumn{2}{|c|}{ Death-1† } & \multicolumn{2}{|c|}{ Death-2 } & \multicolumn{2}{|c|}{ Death-3 } & \multicolumn{2}{|c|}{ Death-5 } & \multicolumn{2}{|c|}{ Death-10 } & \multicolumn{2}{|c|}{ Death-15 } & \multicolumn{2}{|c|}{ Death-20 } & \multicolumn{2}{|c|}{ Death-25 } \\
\hline & Obs & $\operatorname{Exp}$ & Obs & $\operatorname{Exp}$ & Obs & $\operatorname{Exp}$ & Obs & $\operatorname{Exp}$ & Obs & $\operatorname{Exp}$ & Obs & $\operatorname{Exp}$ & Obs & $\operatorname{Exp}$ & Obs & $\operatorname{Exp}$ \\
\hline $\begin{array}{l}\text { Death-1 } \\
\text { Death-2 } \\
\text { Death-3 } \\
\text { Death-5 } \\
\text { Death-10 } \\
\text { Death-15 } \\
\text { Death-20 } \\
\text { Death-25 }\end{array}$ & 16 & $21 \cdot 6$ & $\begin{array}{l}25 \\
50\end{array}$ & $\begin{array}{l}35.9 \\
71.8\end{array}$ & $\begin{array}{r}33 \\
67 \\
100\end{array}$ & $\begin{array}{r}48 \cdot 7 \\
98 \cdot 4 \\
145 \cdot 8\end{array}$ & $\begin{array}{r}48 \\
98 \\
150 \\
250\end{array}$ & $\begin{array}{r}63.9 \\
135.7 \\
209 \cdot 7 \\
343.3\end{array}$ & $\begin{array}{r}48 \\
105 \\
173 \\
335 \\
654\end{array}$ & $\begin{array}{r}68 \cdot 6 \\
150 \cdot 3 \\
243 \cdot 8 \\
454 \cdot 1 \\
906 \cdot 2\end{array}$ & $\begin{array}{r}335 \\
729 \\
1048\end{array}$ & $\begin{array}{l}455 \cdot 6 \\
1016 \\
1478\end{array}$ & $\begin{array}{l}1126 \\
1454\end{array}$ & $\begin{array}{l}1593 \\
2052\end{array}$ & $\begin{array}{l}1523 \\
1936\end{array}$ & $\begin{array}{l}2158 \\
2611\end{array}$ \\
\hline
\end{tabular}
\#A pair of cases were considered to be in "contact" if, on 1 January of a year in which one was "infectious" and the other "susceptible", they were living within
$10 \mathrm{~km}$ of each other. Each year for which this was true counted as one contact.

tThat is, the period of susceptibility was assumed to be from one year before death up to the time of death. 
Table 6 Geographical proximity of places of residence of cases of Creutzfeldt-Jakob disease in England and Wales. Analysis based on 92 cases diagnosed in the period 1980-84 and 184 matched controls

\begin{tabular}{|c|c|c|c|c|c|c|c|}
\hline \multirow{2}{*}{$\begin{array}{l}\text { Assumed } \\
\text { susceptible } \\
\text { period }\end{array}$} & \multirow{2}{*}{$\begin{array}{l}\text { Assumed } \\
\text { infectious } \\
\text { period }\end{array}$} & \multirow[b]{2}{*}{ Contact measure } & \multicolumn{5}{|l|}{ Distance } \\
\hline & & & $<1 \mathrm{~km}$ & $<5 \mathrm{~km}$ & $<10 \mathrm{~km}$ & $<20 \mathrm{~km}$ & \\
\hline $\begin{array}{l}\text { First year of life } \\
\text { Life } \\
\text { Life }\end{array}$ & $\begin{array}{l}\text { Life } \\
\text { Life } \\
\text { Life }\end{array}$ & $\begin{array}{l}0 \text { or } 1 \\
0 \text { or } 1 \\
1 \text { per year of contact }\end{array}$ & $\begin{array}{cc}11 & (10 \cdot 7) \\
132^{\star} & (82 \cdot 4) \\
1614 & (1186)\end{array}$ & $\begin{aligned} 41 & (29 \cdot 2) \\
276^{\star} & (191 \cdot 6) \\
3874 & (3071)\end{aligned}$ & $\begin{array}{cl}110^{\star} & (73 \cdot 2) \\
528 & (412.9) \\
9140 & (7552)\end{array}$ & $\begin{array}{l}272^{\star} \\
1024 \\
22996\end{array}$ & $\begin{array}{l}(175 \cdot 7) \\
(929 \cdot 6) \\
(19929)\end{array}$ \\
\hline
\end{tabular}

${ }^{\star} \mathrm{p}<0.05$.

In the 1970-79 data there was no strong tendency for cases occurring close together in time to reside closer to each other than would be expected by chance. An excess of pairs of cases was found who resided within $20 \mathrm{~km}$ of each other and had disease onset between six months and three years apart (178 pairs, 154.0 expected; $\mathrm{p}<0.05) .^{2}$ In the $1980-84$ series there were 109 such pairs of cases against 102.4 expected (table 3 ) and thus these data offer little support for the earlier finding and, overall, the evidence for space-time clustering is unconvincing. When all of the cases for the period 197084 were considered together a few statistically significant excesses were observed (table 4) but none of these were highly significant and, as a variety of different possible "critical" time and space distances were examined, it would not be surprising if a few spurious associations achieved statistical significance.

In general, cases of a disease caused by an infectious agent are likely to show space-time clustering only if associated cases are expected to have their disease onsets close to each other in time. If the incubation period is long, as in $\mathrm{Kuru}^{16}$ or in CJD following infection by the subcutaneous route, ${ }^{17}$ then even if there is direct case-to-case transmission onset of associated cases may be separated by several years and space-time clustering is unlikely to be detected.

More direct evidence of person-to-person transmission was sought by examining whether cases of CJD had lived closer to other cases of the disease at various times in their lives than would be expected by chance, as assessed by similar analyses involving matched control patients. No striking or statistically significant excesses of such contacts were found for a variety of assumed susceptible and infectious periods up to 25 years before the onset of the disease (table 5). This observation must be interpreted cautiously, however, with respect to inferences about person-to-person transmission. Firstly, we were able to include in these analyses only patients diagnosed in a five year period and it is possible that if the interval between infection and disease onset is long then many of these patients may have "caught" the disease from a patient not included in the series (whose onset was before or after 1980-84). Secondly, we were able to include in the analyses only 92 of the 122 cases diagnosed between 1980-84 and this will further weaken the statistical power of the analyses. Thirdly, the likelihood of contact between cases is measured only very indirectly by the locations of their places of residence. Fourthly, the method of selecting the matched controls (from the same hospital as the cases), while desirable for the purposes of comparing other exposures that might increase the risk of $\mathrm{CJD},{ }^{10}$ may have biased against finding clustering of places of residence of cases compared with controls, as those in a case-control trio are likely to have lived in the same area, at least at the time of diagnosis. Fifthly, and perhaps most importantly, it seems very unlikely that a disease with such a low incidence rate (less than 1 per million per year) could be perpetuated by direct transmission of the agent from case to case.

For the reasons given above it was surprising to find evidence of geographical proximity of places of residence of cases when cases were assumed to be "infectious" throughout life and to have "caught" the disease either in infancy or at any period of life (table 6). On further investigation of these associations it was found that the probable explanation for the clustering described was that cases were more likely to have been born in London than controls. Of the 86 cases with known place of birth in England and Wales, $15\left(17^{\circ}{ }_{0}\right)$ were born within $10 \mathrm{~km}$ of Westminster, whereas only $14(8 \%)$ of 169 controls gave this area as their place of birth $(\mathrm{p}<0.05)$.

Although the results must be interpreted with caution, this study does not provide supportive evidence for case-to-case transmission of CJD, despite examining for evidence of potential contact throughout life. Lateral transmission has occurred in rare iatrogenic cases ${ }^{9}$ but such a mechanism of transmission can be invoked in only a small minority of cases. The largely negative findings in previous epidemiological surveys of CJD has led to the proposition that the CJD agent is integrated within the genome of affected patients. ${ }^{8}$ Any new theory must, however, be consistent with the epidemiology of CJD, including the age distribution, the female excess of cases observed in systematic surveys, ${ }^{235}$ and the tantalising but inconclusive evidence of lateral transmission. The development of CJD in three patients marrying into infected families, ${ }^{346}$ the rare geographic clusters of cases, ${ }^{67}$ the increased incidence in urban Paris, ${ }^{18}$ and the disturbing report of affected pathology technicians, ${ }^{19} 20$ although possibly coincidental, cannot be readily explained on the basis of a genetically integrated agent. Other possible explanations for the distribution of $\mathrm{CJD}^{9}$ include more widespread infection than indicated by the number of cases of CJD, either because of unrecognised atypical cases of long duration ${ }^{21}$ or transmission from an unaffected carrier of the agent. The potential for such cross-infection is underlined by the report of preclinical CJD in a recipient of 
human growth hormone. ${ }^{22}$ The discovery of a biological marker for such cases remains an important objective and might allow a better understanding of the currently unexplained epidemiology of Creutzfeldt-Jakob disease.

1 Gibbs CJ, Gajdusek DC, Asher DM, Beck E, Daniel PM, Matthews WB. Creutzfeldt-Jakob disease (spongiform encephalopathy); transmission to the chimpanzee. Science encephalopathy)

2 Will RG, Matthews WB, Smith PG, Hudson C. A retrospective study of Creutzfeldt-Jakob disease in England and Wales, 1970-1979 II: Epidemiology. J Neurol Neurosurg Psychiatry 1986;49:749-55.

3 Brown P, Cathala F, Raubertas RF, Gajdusek DC, Castaigne P. The epidemiology of Creutzfeldt-Jakob disease: conclusion of a 15 year investigation in France and review of the world literature. Neurology 1987;37: 895-904.

4 Galvez S, Masters CL, Gajdusek DC. Descriptive epidemiology of Creutzfeldt-Jakob disease in Chile. Arch Neurol 1980;37:11-4.

5 Kovanen K, Haltia M. Descriptive epidemiology of Creutzfeldt-Jakob disease in Finland. Acta Neurol Scand 1988; feldt-Jakob

6 Will RG, Matthews WB. Evidence for case-to-case transmission of Creutzfeldt-Jakob disease. J Neurol Neurosurg Psychiatry 1982;45:235-8.

7 Mayer V, Orolin D, Mitrova E. Cluster of Creutzfeldt-Jakob disease and presenile dementia. Lancet 1977;ii:256.

8 Baker HF, Ridley RM, Crow TJ. Experimental transmission of an autosomal dominant spongiform encephalopathy: does the infectious agent originate in the human genome? Br Med J 1985;291:299-302.

9 Brown P. The clinical neurology and epidemiology of Creutzfeldt-Jakob disease, with special reference to iatrogenic cases. In: Novel infectious agents and the central nervous system. Ciba Foundation Symposium, 1988:3-23.
10 Harries-Jones R, Knight R, Will RG, Cousens $\bar{S}$, Smith $\bar{P} \bar{G}$, Matthews WB. Creutzfeldt-Jakob disease in England and Wales 1980-1984: a case-control study of potential risk factors. J Neurol Neurosurg Psychiatry 1988;51:1113-9.

11 Will RG, Matthews WB. A retrospective study of Creutzfeldt-Jakob disease in England and Wales, 1970-1979. I. Clinical features. J Neurol Neurosurg Psychiatry 1984; 47:134-40.

12 Salazar AM, Masters CL, Gajdusek DC, Gibbs CJ Jr. Syndromes of amyotrophic lateral sclerosis and dementia: Syndromes of amyotrophic lateral sclerosis and dementia:
relation to transmissible Creutzfeldt-Jakob disease. Ann relation to transmissib
Neurol 1983;14:17-26.

13 Knox G. Detection of low intensity epidemicity: application to cleft lip and palate. Br J Prev Soc Med 1963;17:121-7.

$14 \mathrm{Knox}$ G. Epidemiology of childhood leukaemia in Northumberland and Durham. Br J Prev Soc Med 1964;18: 17-24.

15 Pike MC, Smith PG. A case-control approach to examine diseases for evidence of contagion, including diseases with long latent periods. Biometrics 1974;30:263-79.

16 Klitzman RL, Alpers MP, Gajdusek DC. The natural incubation period of Kuru and the episodes of transmission in three clusters of patients. Neuroepidemiology 1984;3:3-20.

17 Brown P. Human growth hormone therapy and CreutzfeldtJakob disease: a drama in three acts. Pediatrics 1988;81: 85-92.

18 Raubertas RF, Brown P, Cathala F, Brown I. The question of clustering of Creutzfeldt-Jakob disease. Am J Epidem 1989;129(1):146-54

19 Miller DC. Creutzfeldt-Jakob disease in histopathology technician. New Engl J Med 1988;318:853.

20 Sitwell L, Lach B, Atack E, Atack D, Izukawa D. Creutzfeldt-Jakob disease in histopathology technician. Ner Engl J Med 1988;318:854.

21 Davanipour Z, Alter M, Coslett HB, Sobel E, Kundu S, Hoenig EM. Prolonged progressive dementia with spongiform encephalopathy: a variant of CreutzfeldtJakob disease? Neuroepidemiology 1988;7:56-65.

22 New MI, Brown P, Temeck JW, Owens C, Hedley-Whyte ET, Richardson EP. Preclinical Creutzfeldt-Jakob disease discovered at autopsy in a human growth hormone discovered at autopsy in a human
recipient. Neurology $1988 ; 38: 1133-4$. 